ISSN 1676-3742

\title{
A Biotecnociência diante da morte. A sagrada vulnerabilidade humana
}

Waldir Souza

\section{Resumo}

A técnica, como práxis, configura a relação instrumental da pessoa com o mundo. Os conhecimentos, a biotecnociência e as técnicas dos seres humanos não são onipotentes, pois há limites que devem ser respeitados. A morte diz respeito ao próprio ser do ser humano, finaliza sua existência. Para o ser humano encontrar seu verdadeiro ser autêntico é necessário reconhecer o sofrimento, a dor, a possibilidade da morte e assumi-la. Eis aí, a sagrada vulnerabilidade humana. Hoje temos, na verdade a dicotomia, a separação irreversível entre a capacidade técnica e a capacidade de discernimento. É necessário que os profissionais da saúde pensem suas capacidades biotécnico-científicas na relação com as decisões éticas e existenciais. Só assim haverá as condições necessárias para uma relação dialógica entre o conhecimento analítico e a sacramentalidade da vida.

Palavras-chave: Teologia, Bioética, Biotecnologia, Antropologia, Vulnerabilidade, Sofrimento, Morte. 


\begin{abstract}
The technique, as praxis, configures the person's instrumental relation with the world. Knowledge, biotechnology and techniques from human beings are not omnipotent, for there are limits that must be respected. Death concerns the own being of the human being, since it ends its existence. So that human being finds its truth authentic being it is necessary to realize the suffering, the pain, the possibility of death and assume it. There is the sacred human vulnerability. Today we have in fact a dichotomy, the irreversible separation between the technique capability and the capability of discernment. It is necessary that the professionals of health think their biotechnical-scientific capabilities in relation to the ethics and existential decisions. Just so there will be necessary conditions for a dialogical relation between analytical knowledge and the sacramentality of life.
\end{abstract}

Keywords: Theology, Bioethics, Biotechnology, Anthropology, Vulnerability, Suffering, Death.

\title{
1. Introdução
}

A cultura pós-moderna é determinada pela lógica da biologia e da informação. O sonho maior a ser alcançado pela biotecnologia é superar os limites do tempo e do espaço. Os organismos biológicos deverão ser reduzidos aos sistemas de informação. Todas as coisas vistas como padrões de mensagem que se perpetuam. Na cosmologia pós-moderna, o corpo é apenas um suporte e um arquivo para guardar informações. $\mathrm{O}$ desejo de imortalidade toma contornos religiosos, apesar de se negar a visão tradicional de eternidade do cristianismo. Não há mais verdades permanentes, nem mesmo a morte e a imortalidade são consideradas realidades inevitáveis. Esse pensamento é possível porque a natureza é renovada pela intervenção genética dos seres humanos. A partir disso, a natureza é criação dos seres humanos e não de Deus. Os seres humanos recriam o mundo e não há mais lugar para as verdades universais e para um Deus fora do ser humano. ${ }^{1}$

O corpo não pode ser reduzido à sua dimensão físico-material, limitando a vida a seu significado biológico. Encarar o corpo como expressão da pessoa,

${ }^{1}$ WESTPHAL, Euler Renato. Ciência e Bioética. Um olhar teológico. São Leopoldo: Editora Sinodal, 2009, p. 68. 
como sujeito, irá significar levar em consideração outras dimensões da vida. É dessa maneira que o ser humano expressa-se, torna-se presente, exterioriza-se pelo corpo. A vida segundo o espírito manifesta-se como a vida propriamente humana. Ela o é justamente em virtude da correspondência transcendental entre o espírito e o ser. Com efeito, viver para os seres vivos é seu próprio existir. E como o ser humano existe em sua abertura transcendental para a universalidade do ser ou em sua adequação ativa como ser, o ser humano existe verdadeiramente enquanto espírito, ou a vida propriamente humana é a vida segundo o espírito.

Sob dois aspectos, a vida segundo o espírito se apresenta como a fonte originária da qual flui o verdadeiro ser do ser humano: sob o aspecto da presença e sob o aspecto da unidade. Só o espírito, com efeito, é presente a si mesmo em virtude de sua reflexividade essencial e, por conseguinte, só a vida segundo o espírito é, para o ser humano, vida de presença a si mesmo: de conhecimento de si e de autodeterminação, vida racional e livre. É vivendo segundo o espírito que o ser humano vive humanamente a vida corporal e a vida psíquica. ${ }^{2}$

A dimensão espiritual abre o ser humano para realidades que estão além de sua estrutura somática e psíquica. Revela a sua sagrada vulnerabilidade. Trata-se do âmbito do sentido da vida que transcende a pura configuração histórico-existencial. Assim, a doença, a dor, o sofrimento e a própria morte recebem uma nova significação que ajuda a superar e a integrar essas realidades adversas. ${ }^{3}$

\section{Progresso biotecnocientífico e antropologia}

A técnica, como práxis, configura a relação instrumental da pessoa com o mundo; se poderia dizer que ela é o prolongamento e o aumento da potência do corpo. Por milênios, o ser humano procurou instrumentos para incrementar a sua força muscular; no tempo atual, o ser humano inventou meios para aumentar a potência do sistema nervoso central: não mais apenas a força muscular, mas também a força mental. Como se verá, nem todo pensamento quantificável é de cálculo, redutível a formulação. Entretanto, abriu-se uma nova era, a da infor-

\footnotetext{
2 JUNGES, José Roque. Bioética. Perspectivas e Desafios. Coleção Focus. São Leopoldo: Editora Unisinos, 1999, p. 75-86.

${ }^{3}$ JUNGES, José Roque. As Interfaces da Teologia com a Bioética. In: Perspectiva Teológica. 37 (2005), p. 115-116.
} 
mática e da robótica, na qual as forças de dominação do mundo cresceram e o cérebro humano teve sua capacidade aumentada pela máquina. ${ }^{4}$

Que tipo de saber é aquele que entende o corpo humano como uma configuração orgânica condenada à obsolescência, convertendo-o em um objeto da pós-evolução? Segundo o sociólogo português Hermínio Martins ${ }^{5}$, a tecnociência tem uma vocação fáustica (o mito de Fausto) ${ }^{6}$, cuja meta consiste em ultrapassar a condição humana. Por isso, nos saberes hegemônicos contemporâneos é possível detectar certas tendências "neognósticas", que

\footnotetext{
${ }^{4}$ SGRECCIA, Elio. Manual de bioética I. São Paulo: Edições Loyola, 2002, p. 40-46.

${ }^{5}$ MARTINS, Hermínio. Hegel, Texas: temas de filosofia e sociologia da Técnica; Tecnologia, Modernidade e Política. In: Hegel, Texas e outros ensaios de teoria social. Lisboa: Edições Século XXI, 1996.

${ }^{6}$ Marshall Berman relê o Fausto de Goethe como a primeira e melhor tragédia do desenvolvimento. Ele faz um interessante resgate do mito de Fausto e contextualiza historicamente a época em que Goethe escreveu-o. Em sua releitura, Fausto expressa como no final do século XVIII e início do século XIX o modernismo surgiu. O processo de transformação de Fausto se divide em três metamorfoses sugeridas por Berman: $1^{\text {a }} \mathrm{O}$ sonhador, $2^{\mathrm{a}} \mathrm{O}$ amador e $3^{\mathrm{a}} \mathrm{O}$ fomentador. Na primeira fase, Fausto seria um sonhador. Tinha desenvolvido o intelecto e o espiritual que o levaram ao conhecimento e ao isolamento. Ele agora deseja se expressar através de ações no mundo. O que o fez sentir-se dividido entre vida interior e vida exterior seria a consequência de ele possuir uma cultura dinâmica e viver numa sociedade estagnada. Ele representaria os homens que fizeram parte da cultura moderna que a Divisão do Trabalho, a Renascença e a Reforma criaram e desenvolveram mas mantiveram inacessível ao mundo. Na segunda metamorfose, Fausto é um amador que passou por uma grande metamorfose. Mudou de papel social e status, está charmoso e autoconfiante, tem dinheiro e está livre para se mover, seduzir e enfrentar sua cidade tradicional (o pequeno mundo). Em sua terceira metamorfose, Fausto seria o fomentador, uma figura ambígua porque destrói e constrói. Seus vários projetos visam o coletivo. Ele representa um herói moderno arquetípico - fomentador - mas também representaria um herói trágico porque ironicamente seu desejo de crescimento pessoal e progresso social com o mínimo de sacrifício humano é transgredido no momento em que ele explora seus empregados inclusive passando por cima de seus limites humanos a fim de produzir e construir. BERMAN, Marshall. Tudo o que é sólido desmancha no ar. A aventura da modernidade. São Paulo: Companhia das Letras, $17^{\mathrm{a}}$ edição, 2000, p. 360.

${ }^{7}$ Em história das religiões, reserva-se o nome de gnose (em grego gnôsis, conhecimento) ao conjunto das doutrinas heréticas que nos séculos II e III puseram em perigo grave a unidade do cristianismo nascente, embora o termo tenha sido usado algumas vezes pelos padres da igreja para designar a sua própria doutrina. A gnose herética é, aliás, parcialmente anterior à fixação do dogma pelos concílios. Não se deve incluir na gnose, nem as doutrinas de Marcião (simples radicalismo que opunha o Novo Testamento ao Antigo e que pregava a abstinência) nem as de Ario (que mais tarde defenderá que Cristo era apenas homem). O maniqueísmo, pelo contrário, deve muito à gnose. Os diversos gnosticismos apareceram inicialmente na Síria e sobretudo em Alexandria, de onde se espalharam para o Ocidente (Roma, Lyon, Espanha...). As suas doutrinas são uma mistura de mitos anatolianos, de tradições apócrifas respeitantes a Jesus, de especulações mágicas de origem iraniana (e, em menor grau, egípcia); finalmente, há também uma forte tonalidade platônica nas mais sistemáticas (Basílides, Valentim, Carpócrates). Houve gnósticos judeus e gnósticos paganizantes, ou mesmo pagãos (contra os quais Plotino polemizou). Deste caos destacam-se algumas idéias centrais: a gnose é uma tentativa, quase única no Mundo, de salvação
} 
rejeitam a organicidade e a materialidade do corpo humano para procurar, na sua superação, um ideal ascético, artificial, virtual e imortal.

Os conhecimentos e as técnicas dos seres humanos não são onipotentes; seus "dedos profanos" não podem perturbar todos os âmbitos, pois há limites que devem ser respeitados. Como se depreende logicamente de seus postulados, o progresso dos saberes e das ferramentas prometéicas redunda em um certo "aperfeiçoamento" do corpo, porém este será sempre natural e não-transcendental, ou seja, não pretenderá ir além dos limites impostos pela natureza humana. Pois, de acordo com essa visão, os artefatos técnicos constituem meras extensões, projeções e amplificações das capacidades próprias ao corpo humano. É nesse ponto que a tecnociência de inspiração prometéica (o mito de prometeu $)^{8}$ se detém, sem pretender ultrapassar o umbral

religiosa pelo conhecimento intelectual sem dom direto da graça. O princípio transcendente nem sequer é denominado Deus, mas "Inefável" ou "Abismo" ou "Silêncio". Apesar de uma mistura de práticas mágicas e de fantasmas (dramatizadas sem "evangelhos" e em "apocalipses", alguns dos quais recentemente descobertos), a gnose influenciou não só o pensamento ortodoxo, que combatia, mas também outras heresias (inclusive na Idade Média) e alguns pensadores do Islã. $\mathrm{O}$ hermetismo do Renascimento e o iluminismo devem-lhe igualmente muito, vindo por seu intermédio, a exercer um papel na história da filosofia. LEGRAND, Gerard. Dicionário de Filosofia. Lisboa: Edições 70, 1986, p. 193-194. Quando se fala em "neognóstica", são algumas tendências humanas de resposta e superação diante da sua própria criação (a realidade tecnociêntifíca), com características idênticas aos elementos supracitados (gnose, gnósticos).

${ }^{8}$ A ação do Prometeu acorrentado transcorre numa região desolada da Cítia. Hefesto (o deus do fogo), o Poder e a Força, divindades auxiliares de Zeus, chegam arrastando o titã Prometeu, vítima da ira deste último deus. Hefesto prega-o num rochedo, observado pelo Poder, que vigia o deus do fogo, constrangido com sua missão, e o anima com a alegação de que Prometeu se rebelara contra a vontade divina com o intuito de ajudar a humanidade primitiva. Cumprida a missão, Hefesto, o Poder e a Força retiram-se abandonando Prometeu em sua agonia solitária. Rompendo o silêncio, o titã filantropo proclama a sua indignação diante do céu e da terra em sua volta. As ninfas do mar (as Oceanides) tentam animar Prometeu, que lhes conta como Zeus, graças a ele, conseguiu derrotar os outros titãs e tornar-se o novo soberano dos deuses. Isto feito, Zeus consolidou seu poder absoluto e resolveu destruir a humanidade para criar uma nova raça. Prosseguindo em sua narração Prometeu diz que, por amor às criaturas humanas, conseguiu salvá-las da destruição e lhes deu o fogo por ele roubado do céu, permitindo assim o início da civilização. Prometeu relembra as artes por ele inventadas para aliviar as misérias da condição humana. Entra em cena Hermes, o deus mensageiro de Zeus, pedindo ao infeliz titã para revelar-lhe o segredo fatídico em relação à queda de Zeus. Tratado desdenhosamente por Prometeu, Hermes anuncia-lhe torturas ainda mais cruéis: a águia que devoraria a cada dia seu fígado, que se recomporia também diariamente, e um cataclismo que o lançaria no Hades. Tanto prometeu como as Oceanides desaparecem juntamente no cataclismo. Provavelmente a chave para o melhor entendimento da tragédia é o nome de seu personagem principal: o progresso da humanidade se deveu à capacidade dos homens de "pensar antes de fazer" (literalmente Prometheus significa "aquele que pensa antes"). Esta chave torna mais compreensível o longo discurso de Prometeu sobre o bem que ele fez à humanidade em seus primórdios. KURY, Mário da Gama. In: Ésquilo; Sófocles; Eurípides. Prometeu acorrentado. 2. ed. Rio de Janeiro: J. Zahar, 1998, p. 9-12 (A tragédia grega ; v. 6). 
da vida. ${ }^{9}$ Segundo Paula Sibilia, "a vida orgânica nunca será compreendida de modo tão fundamental quanto os mundos físico e humano, ambos os quais são suscetíveis de indefinida mecanização de uma maneira que a vida orgânica não o seria nunca". ${ }^{10}$

Para esse modo de entender a tecnociência, o reino do vivo manter-se-ia gloriosamente refratário à mecanização, embora não imune às depredações humanas. Mas esta recusa da vida orgânica em se deixar penetrar pelas ferramentas tecnocientíficas constitui, obviamente, uma forte limitação para o conhecimento e as potencialidades humanas, e hoje é inegável a ostensiva refutação dessa tese. Os avanços mais recentes na área biotecnológica, com toda sua artilharia informática a serviço do "deciframento da vida", se propõem precisamente a vencer as resistências que esse derradeiro vestígio do caráter sagrado da natureza costuma opor ao instrumental tecnocientífico. ${ }^{11}$

A pessoa humana sempre deve permanecer o objetivo último, deve ser sempre o objetivo e o critério. Dinheiro e capital sempre são um meio, assim como o trabalho também é meio. Também a ciência, técnica e indústria são meios. Em si, também eles, de modo algum, estão livres de valores. Não são "neutrais". Eles devem ser avaliados e utilizados na medida em que servem à pessoa humana e seu desenvolvimento. De acordo com isso, a manipulação de genes humanos só é lícita na medida em que esta dá proteção, preservação e humanização da vida humana. A pesquisa com embriões descartáveis é um experimento humano que deve ser considerado desumano e como tal deve ser rejeitado. 12

A grande questão aqui levantada por Hans Küng é quando a ciência, a técnica, a indústria, o comércio, a política (criação humana) transformam o ser humano em objeto-criatura. Isto deveria ser rejeitado. $\mathrm{O}$ desenvolvimento tecnológico da medicina (extrema tecnificação clínica; crescentes políticas de coletivização da saúde; consciência dos direitos do enfermo; importância

${ }^{9}$ SIBILIA, Paula. O homem pós-orgânico. Corpo, subjetividade e tecnologias. Rio de Janeiro: Relume Dumorá, 2003, p. 42-46.

${ }^{10}$ MARTINS, Hermínio. Hegel, Texas: temas de filosofia e sociologia da Técnica; Tecnologia, Modernidade e Política. In: Hegel, Texas e outros ensaios de teoria social. Lisboa: Edições Século XXI, 1996. apud. SIBILIA. O homem pós-orgânico, p. 46.

${ }^{11}$ SIBILIA. O homem pós-orgânico, p. 46-47.

${ }^{12}$ KÜNG, Hans. Projeto de ética Mundial: Uma moral ecumênica em vista da sobrevivência humana. $3^{a}$ ed. São Paulo: Paulinas, 2001, p. 54. 
da prevenção das doenças) e os progressos da ciência biológica (engenharia genética; técnicas de reprodução humana; transplantes de órgãos; intervenção em estados intersexuais; progressos técnicos quanto à reanimação e à diagnose pré-natal) colocam novos desafios que a tradicional ética médica não consegue responder por seu caráter de pura deontologia profissional. Para tanto, é necessário um saber mais global e interdisciplinar e, principalmente, uma argumentação mais consistente. Assim surge a bioética como um estudo sistemático das dimensões morais das ciências da vida e da saúde.

A bioética torna-se um fórum de discussão e de construção de consensos sobre os limites e objetivos de uma pesquisa científica que envolve seres humanos, de uma prática médica a serviço da beneficência e autonomia do enfermo, de uma política que assegure condições de saúde para todos. Precisa envolver toda a sociedade civil como o pensar e o agir cristão porque a defesa da vida e a promoção da saúde são do interesse e salvaguarda de todos. ${ }^{13}$

É um dado comprovado que existe uma interdependência entre o progresso tecnológico e as mutações socioculturais do ser humano sobre a Terra. Daí surgem duas questões a serem refletidas:

$1^{\boldsymbol{0}}$. O "progresso", que tecnicamente é linear, comporta da mesma maneira e automaticamente um aperfeiçoamento antropológico?

$2^{\boldsymbol{a}}$. A mudança que retorna sobre o tipo de vida do ser humano por causa do progresso científico é uma transformação que o próprio ser humano pode dominar?

Nesse sentido, a teologia pode apontar alguns elementos bastante elucidativos. A primeira observação é que o progresso técnico-científico é linear, por isso progressivo, mas, ao mesmo tempo, redutivo. Essa linearidade quantitativa não pode senão "reduzir" o real à relações matemáticas, causais, quantificáveis. Desta forma, os aspectos qualitativo, ontológico, finalístico da realidade, são isolados. A causalidade ignora a finalidade, a técnica fica sem sentido de direção e de valor.

A ética do impulso está presente na ciência e na técnica, mas ela não conhece a ética dos meios e dos fins, a deontologia e a teleologia. É por isso

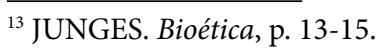




\section{que várias correntes filosóficas - o existencialismo, ${ }^{14}$ a fenomenologia, ${ }^{15} \mathrm{o}$ personalismo, ${ }^{16}$ as próprias escolas de epistemologia ${ }^{17}$ - exigiram e exigem}

${ }^{14}$ Nome genérico de diversas doutrinas que tem em comum a afirmação do primado da existência
e da sua irredutibilidade ao pensamento conceitual tradicional. Os filósofos existencialistas têm
em comum a descoberta de que o homem não é antes de mais um ser dotado de razão, mas um
"nada que aniquila", isto é, um existente sem significado que "esvazia" o Mundo, com a sua simples
presença, de qualquer sentido necessário ou a priori. Efetivamente, não há nenhum grande filó-
sofo do passado, mesmo dos mais racionalistas, que não tenha também ele aprendido a medida
da "singularidade" do homem. O existencialismo transforma-a em princípio: princípio do estudo
das "atitudes fundamentais" (Jaspers) ou do compromisso por meio do qual o homem, condenado
à partida a uma liberdade ilimitada e à angústia metafísica, escolhe ser ele mesmo o seu próprio
sentido (Sartre). LEGRAND. Dicionário de Filosofia, p. 162 .

${ }^{15}$ Designação, que remonta ao século XVIII, do estudo das "aparências" ou dos "fenômenos" (em sentido kantiano): o seu emprego específico por Hegel (Phénoménologie des Geistes, 1807) deriva daqui. Nestas obras de dupla leitura, Hegel descreve historicamente e psicologicamente as "aparições" Hoje diz-se apenas do método e do sistema (fenomenologia transcendental) próprios de Husserl e dos seus genuínos sucessores. Edmund Husserl (1859-1938) quis fazer da filosofia uma "ciência rigorosa" (principais obras: Investigações Lógicas, 1900-1901; Idéias e Diretrizes para uma Fenomenologia Pura, 1913; Meditações Cartesianas, 1931;...). O discurso husserliano consiste, transpondo estes "objetos ideais" para a lógica, fazê-los "apanhar" pela consciência munida de intencionalidade. Rejeita o modelo da aproximação psicofisiológica, depois o modelo histórico e (de passagem) a formalização aritmética. Conclui com a renovação da psicologia do ego, enriquecida com a distinção entre o "vivido real" e o "vivido inatual", sendo o "atual" tomado tanto em sentido temporal como no sentido aristotélico. A existência do concreto (o "vivido" em geral) aparece como a tomada de consciência de uma percepção incluindo-se a ela mesma, que Husserl chama, muitas vezes, o "mundo". A fenomenologia husserliana não só influenciou pensadores de "ciências humanas" (Max Weber, Max Scheler, ...) como também o existencialismo (Heidegger, e mais ainda Sartre) e, finalmente, a busca de elucidação das sigificações ideais em geometria e na lógica (Suzanne Bachelard). O seu representante mais original (relacionou-se com a Gestalteoria) mas também a mais impressionista na procura do concreto terá sido Merelau-Ponty (1908-1961). LEGRAND. Dicionário de Filosofia, p. 172-173.

${ }^{16}$ Mais estado de espírito que doutrina, definido já antes da 2a Guerra Mundial por Emmanuel Mounier, e que se difundiu entre 1945-1950. É uma tentativa de repensar a filosofia cristã, rejeitando qualquer dualismo espiritualista para beneficiar da experiência concreta, e que da simples individualidade passa à noção moral da pessoa nomeadamente através da comunicação das consciências. Bastante intransigente com o marxismo, Mounier rejeita mais decididamente ainda o individualismo "burguês" das filosofias racionalistas. Este pensamento relaciona-se com o existencialismo cristão, e até com agnóstico (Camus), não deixando de exercer uma contínua influência até aos nossos dias. LEGRAND. Dicionário de Filosofia, p. 300-301.

${ }^{17}$ Sinônimo antigo de gnoseologia que se usa com frequência neste sentido, beneficiando do prestígio da prioridade. Hoje em dia, estudo histórico e crítico dos conceitos e das noções de uma ciência particular, no seu desenvolvimento e aplicações. Pode eventualmente desembocar na filosofia das ciências, que poderia designar-se por "epistemologia geral". Surge em certos trabalhos de Bérgson e de Meyerson (autor do "Paradoxo epistemológico"). Desenvolveu-se num sentido "genético" com Piaget, num sentido "relativista" ou "dialético" com Bachelard. LEGRAND. Dicionário de Filosofia, p. 142. 
uma nova síntese entre cultura tecnológica e humanismo, entre ciências experimentais e ciências humanas e sobretudo se pede que a ética apreenda o sentido de direção da civilização e garanta o seu caminho. ${ }^{18}$

Para poder prever as consequências do uso das biotecnologias e ter condições de evitar seus efeitos negativos, é preciso conhecer muito bem as regras da vida em todos os seus níveis de organização: das moléculas às células, aos organismos, às populações de organismos, aos ecossistemas e à biosfera. Naturalmente, é preciso verificar os efeitos de nossas ações em todos esses níveis da realidade, atentando em especial para o que pode acontecer com os seres humanos, seja do ponto de vista individual, seja no que diz respeito às relações sociais. Os aspectos éticos desempenham um papel importante e, portanto, devem ser levados em conta não apenas quando se trata de decidir a vida do ser humano, mas também quando se influi na vida dos seus semelhantes e na dos outros habitantes do planeta Terra. ${ }^{19}$

Num mundo desigual em que Estados aviltados em sua dignidade estão em confronto com gigantes que querem manter seu poder a qualquer custo; em que populações que vivem no limiar a sobrevivência se defrontam com outras que desperdiçam na super-abundância; em que segmentos sociais, como mulheres e as populações negras, não conseguem superar as condições históricas da desigualdade que as oprimem e que, grupos sociais perderam (ou sentem-se ameaçados de perder) suas características socioculturais por força do contato opressivo com a ideologia de mercado: tal fantasma não parece estar longe de se materializar. Na sociedade de mercado globalizada, na qual tudo tem preço, também o dilema existencial se adultera: ter ou não ter, passa a ser a questão. ${ }^{20}$

A ética da tecnologia, por isso, não deve ser considerada simplesmente em função da fase aplicativa, mas também em sua insuficiência radical, em sua ambivalência teleológica e em sua dinâmica de saber-poder, que aumenta cada vez mais e, portanto, também em sua fase elucidativa. Dessa forma, a tecnologia exige ser completada e ter sua referência numa antropologia global na qual possa encontrar o seu papel ao lado das outras dimensões do ser humano. $\mathrm{O}$ essencialmente humano, com as ambivalências e oposições características

\footnotetext{
${ }^{18}$ SGRECCIA, Elio. Manual de bioética I, p. 46-49.

${ }^{19}$ BUIATTI, Marcelo. Biotecnologias. A engenharia genética entre biologia, ética e mercado. São Paulo: Edições Loyola - Paulinas, 2004.

${ }^{20}$ PORTO, Dora. Tecnologia \& ideologia: os dois lados da moeda que produz vulnerabilidade. In. Revista Brasileira de Bioética. Volume 2 - Número 1 - 2006.
} 
do mistério de sua liberdade, a que pertencem às experiências de fortúnio e infortúnio, prazer e dor, bem e mal, nas quais se desdobra a epopéia humana em sua história. A preservação de uma tal essência constitui o dever basilar da ética e da teologia ao tratar da responsabilidade e da vida. ${ }^{21}$

Segundo Jonas, somente o ser vivo, em sua natureza carente e sujeita a riscos, pode ser objeto da responsabilidade. A marca distintiva do ser humano é o fato de ser o único capaz de ter responsabilidade; significa igualmente que ele deve tê-la pelos seus semelhantes, e que realmente ele sempre a tem, de um jeito ou de outro. A faculdade para tal é a condição suficiente para a sua efetividade. Por isso que para Jonas,

ser responsável efetivamente por alguém ou por qualquer coisa em certas circunstâncias (mesmo que não assuma nem reconheça tal responsabilidade) é tão inseparável da existência do homem quanto o fato de que ele seja genericamente capaz de responsabilidade. 22

O que há de se levar em consideração, segundo Jonas, é que a prioridade do ser humano entre os postulantes à responsabilidade humana não tem nada a ver com uma avaliação sobre o desempenho na Terra. O preço da aventura humana é, ressalta Jonas, enorme; e a mesquinharia humana é pelo menos equivalente à sua grandeza. Quando se fala da "dignidade do ser humano" como tal, somente se deve compreendê-la em um sentido potencial, pois em caso contrário tal discurso expressará uma vaidade imperdoável. A possibilidade sempre transcendente, obrigatória por si mesma, precisa ser mantida graças à continuação da existência. Preservar essa possibilidade como responsabilidade cósmica, lembra Jonas, significa precisamente o dever de existir. A primeira de todas as responsabilidades é garantir a possibilidade de que haja responsabilidade. ${ }^{23}$

Para Jonas, a existência da humanidade significa simplesmente que haja vida e que vivam os seres humanos. Que vivam bem é um imperativo que se segue ao anterior. Esse "primeiro imperativo" segundo Jonas, normalmente anônimo, está contido, implicitamente, em todos os outros. Confiada a sua execução imediata ao instinto de procriação, esse imperativo pode manter-se

\footnotetext{
${ }^{21}$ JONAS, Hans. Das Prinzip Verantwortung. Versuch einer Ethik für die technologische Zivilisation. Frankfurt am Main, 1979.

22 JONAS, Hans. O Princípio responsabilidade. Ensaio de uma ética para a civilização tecnológica. Rio de Janeiro: Contraponto Editora; Editora PUC Rio, 2006, p. 176.

${ }^{23}$ JONAS. O Princípio responsabilidade, p. 176-177.
} 
escondido por trás dos imperativos particulares da virtude humana, que tratam de aprimorar a sua significação. Para Jonas, "essa é a causa original de todas as causas que podem ser objeto da responsabilidade comum à humanidade". ${ }^{24}$

Este elemento inato a condição humana é um imperativo criterioso no processo de evolução e subsequentemente nos avanços científicos. Apesar de alguns críticos radicais considerarem grande parte dos avanços da ciência como "perigosos", é impossível imaginar a atual estrutura societária (ou biológica) como eterna e imutável. É compromisso da ciência, pois, preparar o futuro, antecipando-se a ele por meio de descobertas que venham trazer benefícios à espécie humana. A mutabilidade da sociedade e do mundo é uma certeza; a dúvida reside em estabelecer o limite concreto até onde os avanços da ciência devam se verificar. Assumir a responsabilidade é sempre um ato seletivo, e a escolha daquilo que é mais próximo do ser humano, corresponde a finitude da natureza humana.

Não resta dúvida que o caminho está no equilíbrio, na busca de soluções moralmente aceitáveis e praticamente úteis. Para isso, é indispensável que as novidades sejam analisadas caso a caso, em cada contexto social, com responsabilidade e bom senso, respeitando-se certos valores societários e pluralismo moral que, queira ou não, é marca registrada dos dias atuais. Neste sentido, alguns valores nos quais a humanidade e a ciência vêm se pautando nos últimos tempos, deverão ser transformados. Seria preferível que a responsabilidade ética fosse tatuada indelevelmente na equação que determina a liberdade científica; e que a tecnocracia e a mercantilização desenfreada, que submetem a sociedade às suas leis insensíveis, se transformassem exclusivamente em tecnologia saudável a serviço da humanidade. Em outras palavras, trata-se de estimular o desenvolvimento da ciência dentro das fronteiras humanas e, ao mesmo tempo, de desestimulá-la quando passa a avançar na direção de limites desumanos. ${ }^{25}$

Também há de se contemplar a responsabilidade por uma vida (individual ou coletiva) se ocupando antes de tudo com o futuro, bem mais do que com o presente imediato. Isso, segundo Jonas, é verdadeiro em um sentido trivial para toda responsabilidade, mesmo a mais particular, acompanhando-se a evolução de uma tarefa até o fim. Assim expressa Jonas:

\footnotetext{
${ }^{24}$ JONAS. O Princípio responsabilidade, p. 177.

${ }^{25}$ GARRAFA, Volnei. Crítica bioética a um nascimento anunciado. In: Revista Parcerias Estratégicas. Ética das manipulações genéticas: proposta para um código de conduta. Número $16-$ Outubro de 2002. Brasília, p. 121.
} 
...exatamente aqueles efeitos pelos quais o responsável já não poderá responder: a causalidade autônoma da existência protegida é o derradeiro objeto do seu cuidado. Em relação a esse horizonte transcendente, a responsabilidade, mesmo em sua totalidade, não pode ambicionar um papel determinante; pode ambicionar possibilitá-lo (ou seja, prepará-lo e manter aberta a oportunidade). O caráter vindouro daquilo que deve ser objeto de cuidado constitui o aspecto de futuro mais próprio da responsabilidade. Sua realização suprema, que ele deve ousar, é a sua renúncia diante do direito daquele que ainda não existe e cujo futuro ele trata de garantir. À luz dessa amplidão transcendente, torna-se evidente que a responsabilidade não é nada mais do que o complemento moral para a constituição ontológica do nosso Ser temporal.26

Assim, resta dirigir o "fazer", mais uma vez, com prudência e tolerância, entre os apertados limites do necessário e do possível. A sofisticada intervenção tecnocientífica em um meio não só natural como cultural, atravessando por atos de vontade e escolha apaixonada, é tão "humana" quanto à ética, com a qual, nesse pé, pode estabelecer um grande e desafiador diálogo. ${ }^{27}$

Nessa perspectiva, a bioética estuda os avanços recentes da ciência em função, sobretudo do ser humano, que tem a responsabilidade de cuidar como co-criador de toda a vida. Por isso, a referência central é o ser humano, considerando os dois momentos básicos de sua vida, ou seja, o nascimento e a morte. É em torno destas duas fases da vida que hoje a ciência está fazendo seus melhores progressos e, obviamente, colocando problemas éticos inimagináveis antes dessas descobertas.

Fica claro que a pessoa humana é o tema central da bioética. Se tiver um bom entendimento da pessoa, ter-se-á encontrado o caminho de uma resposta aceitável para muitos problemas. O que se constata é que a filosofia e a antropologia divergem sobre o conceito de pessoa. E, dependendo da definição que se lhe dá, os problemas da bioética recebem respostas muito diferentes. ${ }^{28}$

\footnotetext{
${ }^{26}$ JONAS. O Princípio responsabilidade, p. 187.

${ }^{27}$ GARRAFA. Crítica bioética a um nascimento anunciado, p. 122.

${ }^{28}$ PESSINI, Leocir; BARCHIFONTAINE, Christian de Paul. Problemas atuais de Bioética. São Paulo: Centro Universitário São Camilo, Edições Loyola, 2000, p. 67.
} 


\section{A morte como reveladora do mistério da vida}

O ser humano é um ente complexo. Definir o que venha a ser é algo maravilhoso, quando se mergulha no que representa a vida para o ser humano. Qual o sentido da vida? Por que morremos? São perguntas que levam a refletir sobre o mistério da vida e sua complexidade. O ser humano é um ser racional, capaz de sonhar, ter projetos, construir e desenvolver habilidades para lidar com as mais diversas realidades em que cria e vive. Porém, algo o ser humano teme: a morte. Muitos não param para refletir sobre a morte e o seu sentido para a vida. Procuram escapar, procuram compensações, ou seja, o ser humano ainda teme a morte. Algo natural e compreensível, pois todos querem viver e não morrer.

O ser humano é um ser lançado num mundo hostil, isto é, o mundo é um lugar que não acolhe o ser com compaixão e misericórdia. $\mathrm{O}$ mundo recebe o ser humano e não se preocupa com ele, é somente mais um ente lançado na existência em um lugar nada amistoso, porém não é possível existir fora do mundo, portanto, ser é estar no mundo. Tudo realizado pelo ser humano acontece no mundo, não há como fugir. A existência do ser humano é transcendência no estar no mundo. Existir é, essencialmente, transcendência. Desse modo, o ser humano, ao dar significado para o seu habitat, projeta-se nele e utiliza as coisas para transcender..$^{29}$

O ser humano tem na sua constituição ontológica, a abertura para as coisas e faz parte da sua substância estar aberto às coisas e aos outros humanos. Segundo Heidegger,

Tem a necessidade do mundo e das coisas que o constituem e que são a realidade útil, os instrumentos da sua vida e da sua ação. Estar no mundo significa, para ele (ser humano), cuidar das coisas: mudá-las, manipulá-las, repará-las, construí-las, e esta preocupação, por ser características do ser humano enquanto está no mundo, determina também o ser das coisas do mundo. $^{30}$

\footnotetext{
${ }^{29}$ MARTINS, Alexandre Andrade. Consciência de finitude, sofrimento e espiritualidade. In: PESSINI, Leocir; BARCHIFONTAINE, Christian de Paul de (org.). Buscar sentido e plenitude de vida. Bioética, saúde e espiritualidade. São Paulo: Paulinas; Centro Universitário São Camilo, 2008, p. 100.

${ }^{30}$ HEIDEGGER, Martin apud ABBAGNANO, N. História da filosofia. Lisboa: Presença, 1970, p. 197-198.
} 
O ser humano anseia por uma existência autêntica, aberta às estruturas ontológicas para transcender o mundo. Para isso ocorrer, o ser humano deverá ouvir a voz da consciência incitando-o à verdadeira existência. Para isso ocorrer, é preciso voltar à sua ontologia, suas manifestações ônticas e perceber: o ser humano é um ser de possibilidades realizadas dentro da temporalidade, existência marcada pelo intervalo entre o finito e infinito, pela solidão e sociedade, pelo envelhecimento e pela mortalidade.

O ser acaba, morre. A possibilidade por excelência é a morte. Ela diz respeito ao próprio ser do ser humano, finaliza sua existência. A voz da consciência chama-o a si mesmo, ao que é e não pode deixar de ser: um ser para a morte. Para o ser humano encontrar seu verdadeiro ser autêntico é necessário reconhecer a possibilidade da morte e assumi-la. Conceber a morte como parte fundamental do seu ser, compreender a possibilidade inegável da impossibilidade da existência enquanto tal. Porém, tomar consciência da possibilidade da morte não deixa o ser humano inerte, imóvel e sem a menor perspectiva de realização. É justamente o contrário. Abre-o à sua temporalidade e mostra a importância de uma existência autêntica e realizada. ${ }^{31}$

A morte é o que de mais próprio se tem e, ao mesmo tempo, é o que de mais estranho se experimenta. A pergunta pela morte conduz o ser humano ao mistério e à sacralidade da vida. Ela causa embaraço, porque nenhum ser humano que pensa sobre ela experimentou-a em si mesmo. Ela é uma experiência inédita para cada um. A quem, portanto, dirigir a pergunta sobre a morte? A ciência não tem total clareza sobre aquilo que é morte, pois ela não pode ser definida com exatidão. Quando um vivente passa ao estado de morte, isso embaraça os estudiosos das ciências da saúde. Aliás, ela é embaraçosa para todos os seres humanos. Isso é experimentado porque na morte temos o silêncio de Deus e o silêncio do ser humano. ${ }^{32}$

A compreensão de ser para a morte vem acompanhada da angústia. "A angústia é a situação emotiva capaz de manter aberta a contínua e radical ameaça que sai do ser mais íntimo e isolado do ser humano... em presença do nada, da impossibilidade possível da sua existência"33 Coloca o ser humano diante do nada, do fim, da morte. A angústia revela também o sentido autêntico da presença do ser humano no mundo. Ela antecipa o nada, levando a pessoa a compreender sua existência e a transcender no tempo.

\footnotetext{
${ }^{31}$ MARTINS. Consciência de finitude, sofrimento e espiritualidade, p. 100-101.

${ }^{32}$ WESTPHAL. Ciência e Bioética, p. 91-92.

${ }^{33}$ HEIDEGGER apud ABBAGNANO. História da filosofia, p.207.
} 
A morte é um fato, um acontecimento inevitável, inacessível à compreensão humana diante da qual cabe a resignação. O morrer por outro lado, é um processo, uma vivência existencial incomunicável, insistentemente desafiante, que pede uma atitude interior. A sociedade contemporânea tem dificuldade em pensar na questão da morte e do morrer. A morte deixa de ser reconhecida como um aspecto integrante do viver. Não é a morte em si quem causa angústia aos seres humanos, mas a consciência de que um dia ela acontecerá. Por isso, afastando-se dela ou negando a sua existência, o ser humano acredita que dominará e controlará tudo o que termina com a vida. ${ }^{34}$ "O triunfo da medicalização é manter a doença e a morte na ignorância e no silêncio". 35

Porém, a medicina curativa tem aí o seu limite, o seu "fracasso". Não se pode conter tudo, viver eternamente, a morte é inevitável por mais que as taxas demográficas demonstrem que hoje se vive mais. É aqui que está a chave para entender o desafio da morte em nossa sociedade tecnológica e cientificamente equipada.$^{36} \mathrm{~A}$ ciência que se pratica nos dias atuais faz que se considere a morte como um fim, como derrota e se aceite como conceito de perda, de fim, de destruição de sofrimento, a vida perde um sentido maior de viver; pelo contrário, se ela for aceita pelo menos como inevitável, mas como necessária ao crescimento, à evolução, à continuação da vida, à libertação, a vida passará ser vivida com dignidade e plenitude. ${ }^{37}$

"Vida e morte estão intimamente entrelaçadas, conscientemente unidas uma com a outra, não apenas nas culturas primitivas, mas em todas as civilizações, menos a civilização industrial em que estamos imersos" ${ }^{38}$ Hoje se tenta tardar cada vez mais a morte, e ela não é vista como algo natural, dentro de toda a existência humana, constituída do intervalo entre o finito e o infinito. Muitas técnicas são desenvolvidas para não deixar o doente morrer e, quando alguém está perto do fim, a sua autonomia é comprometida; a família não aceita a proximidade do fim e tenta evitá-lo, mesmo à custa de maior

${ }^{34}$ BRITO, Robson Figueiredo. Morte: experiência da vida. In: D’ASSUMPÇÃO, Evaldo A. Biotanatologia e Bioética. São Paulo: Paulinas, 2005, p. 50.

${ }^{35}$ KOVACS apud BRITO. Morte: experiência da vida, p. 51.

${ }^{36}$ KOVACS apud BRITO. Morte: experiência da vida, p. 59

${ }^{37}$ GALENO, Sebastião. Medo da morte, medo da vida? In: D’ASSUMPÇÃO, Evaldo A. (org.). Biotanatologia e Bioética. São Paulo: Paulinas, 2005, p. 66.

${ }^{38}$ LEPARGNEUR, H. Lugar atual da morte: antropologia, medicina e religião. São Paulo: Paulus, 1986, p. 37. 
sofrimento do moribundo. Elizabeth Kübler-Ross ${ }^{39}$ defende que a vontade do paciente deve ser respeitada. Se ele quer morrer naturalmente, que se faça a sua vontade. O paciente terminal tem uma linguagem difícil de ser compreendida, pois muitas vezes não é verbal e isso exige grande atenção, dificultando como saber a vontade do moribundo. O querer uma morte natural, ou não, faz parte da dimensão ontológica do ser. É a compreensão tardia de que um ser para a morte. Não se pode descrever o sentimento, o tamanho do sofrimento do agonizante, mas se tem uma certeza: é uma passagem difícil, principalmente para aqueles que nunca deixaram espaço para alcançar a consciência da finitude. ${ }^{40}$

A morte ainda continua sendo algo incompreensível e inaceitável, pois o ser humano vive em meio a uma supervalorização dos bens temporais, do material e, morrendo, não se pode mais usufruir das coisas proporcionadas pela sociedade tecnológica e consumista. Se o sentido das coisas é o de serem usadas pelo ser humano, com a morte tudo perde o sentido. Nessa perspectiva, as coisas e o ser humano - morto - não existem mais. Sendo assim, não haveria por que ter essa preocupação materialista de, com a morte, não usufruir mais das coisas. O uso das coisas é feito no intervalo da existência. O ser humano atual não aceita essa condição da realidade. Existir é estar no mundo e o mundo só existe enquanto existimos. Ao morrer, tudo acabou. É a possibilidade que faz tudo se tornar impossibilidade. ${ }^{41} \mathrm{O}$ limite das ciências da saúde, da técnica, da biotecnologia, encontram-se na impossibilidade da lógica analítica proporcionar sentido ao sofrimento e à morte. ${ }^{42}$

A morte do ser humano o faz dar maior valor à vida. A possibilidade da morte, e sempre inesperada, dá-nos uma emergente necessidade de fazer bem as coisas sem esperar que outra oportunidade aconteça. As perdas nos dão a exata dimensão dos ganhos. A morte, sendo a perda maior que podemos sofrer, nos faz valorizar a vida. O medo da morte é o medo da vida não vivida. É o medo dos muitos débitos que o ser humano tem para com a sua própria vida, e que a morte o impedirá de saldar. ${ }^{43}$

\footnotetext{
${ }^{39}$ KÜBLER-ROSS, Elizabeth. Sobre a morte e o morrer. São Paulo: Martins Fontes, 1994.

${ }^{40}$ MARTINS. Consciência de finitude, sofrimento e espiritualidade, p. 103-104.

${ }^{41}$ MARTINS. Consciência de finitude, sofrimento e espiritualidade, p. 104.

${ }^{42}$ WESTPHAL. Ciência e Bioética, p. 94.

${ }^{43}$ D’ASSUMPÇÃO, Evaldo A. Sobre o viver e o morrer. Petrópolis: Vozes. 2010, p. 93-108.
} 


\section{A sagrada vulnerabilidade humana ${ }^{44}$}

Viver humanamente significa, pois viver na vulnerabilidade. Um ser vulnerável é um ser quebradiço, cuja integridade esta constantemente ameaçada por elementos externos e internos. O ser humano é um ser pluridimensional e inter-relacional porque tem distintas dimensões ou faces e, além disso, estabelece vínculos diferentes com seu entorno e com seu semelhante. É um ser exposto, e isto significa que deve proteger-se, que deve construir um abrigo, uma capa protetora frente ao mundo e ao entorno. ${ }^{45}$

O ser humano é vulnerável fisicamente, porque está sujeito à enfermidade, à dor e à decrepitude e, precisamente por isso, necessita cuidar-se; é vulnerável psicologicamente porque sua mente é frágil e necessita cuidado e atenção; é vulnerável do ponto de vista social, pois, como agente social que é, é suscetível a tensões e a ferimentos sociais; além disso, é vulnerável espiritualmente, ou seja, sua interioridade pode facilmente ser objeto de instrumentalizações sectárias. Sua estrutura pluridimensional, seu modo relacional, sua vida, seu trabalho, suas ações, seu pensamento, seus sentimentos e, inclusive, suas fantasias são vulneráveis. ${ }^{46}$

Por tudo isso, o ser humano é, em alguns aspectos, muito mais vulnerável que outros seres vivos, mas, em outros aspectos, mais hábil para proteger-se da vulnerabilidade de seu ser. O recém-nascido é, de certo modo, a mais plástica epifania da extrema vulnerabilidade do ser humano. ${ }^{47}$

Na concepção de muita gente, o sofrimento é explicado como uma imposição de Deus ao ser humano. "Vivemos num vale de lágrimas" e portanto, nosso destino é o sofrimento. Este modo de pensar e de interpretar os fatos, tem levado muita gente a uma condição de desespero, de raiva, de depressão e revolta contra o Criador. Na verdade, o ser humano não foi criado para ser infeliz, para sofrer. Se assim fosse, é necessário admitir um Criador imperfeito

\footnotetext{
${ }^{44}$ Por vulnerabilidade entende-se a complexa e frágil relação do ser humano enquanto é uma unidade estrutural de corpo, psiquismo e espírito. A passagem da estrutura para a relação significa a passagem da forma ao conteúdo, da expressão ou do significante ao significado. $\mathrm{O}$ ser situado forma uma totalidade. Ele está situado de acordo com os três modos de presença: mundo, outro e absoluto. Esse corpo orgânico é a condição de possibilidade da presença no mundo; o psiquismo, condição de possibilidade da presença face ao outro; o espírito, condição de possibilidade da presença face ao absoluto. JUNGES. Bioética, p. 75-77.

${ }^{45}$ TORRALBA i ROSELLÓ, Francesc. Antropologia do Cuidar. Petrópolis: Vozes, 2009, p. 57-59.

${ }^{46}$ OWEN, M. J. La sabiduría de la vulnerabilidad humana. In: Dolentium Hominum, 22, (1993), p. 171-173.

${ }^{47}$ TORRALBA i ROSELLÓ. Antropologia do Cuidar, p. 59-60
} 
e sádico. A experiência íntima do amor revela que Deus não é assim. O ser humano ontologicamente foi chamado para ser feliz, se assim não o é, porque usa inadequadamente a sua liberdade. ${ }^{48}$

Há uma grande diferença entre dor e sofrimento. A dor é o resultado de fenômenos físico-químicos que ocorrem em qualquer organismo vivo. Segundo a Associação Internacional de Estudo da Dor, a dor é "uma experiência emocional e sensorial desagradável associada com dano potencial ou total de tecidos, descrita em termos de tais mudanças". ${ }^{49}$ Não é exclusividade da espécie homo sapiens. Mas por que o sofrimento da dor é uma característica exclusiva do ser humano? A dor tem sentido? Qual o sentido da dor?

Pode-se dizer que ela tem vários sentidos como a autoproteção, sinal de alguma alteração, autopunição, crescimento interior, que poderíamos traduzir como dor mental, social e espiritual. Estes aspectos estão inter-relacionados e abrangem a totalidade do ser humano. Na realidade quando estamos na situação de sofrimento a vulnerabilidade humana torna-se mais aguda do que a dor. Desta maneira, podemos estabelecer diferenças entre a dor e o sofrimento. $\mathrm{Na}$ realidade, nem sempre quem está com dor sofre. $\mathrm{O}$ sofrimento é uma questão pessoal. Ele está ligado aos valores da pessoa e a situações circunstanciais que a afetam no seu ser total. ${ }^{50}$ Portanto, o sofrimento é mais global do que a dor, diria que atinge o âmago, a vida na sua plenitude.

O sofrimento traz uma grande lição quando aproxima do próprio ser humano. A apropriação da realidade pessoal e a reação da pessoa são fundamentais para captar a mensagem contida nas situações de dor e sofrimento, interpretando-a ou assimilando-a como oportunidade ou desventura. Tomar nas mãos a situação implica um processo de interiorização no qual a pessoa passa a apropriar-se do seu problema, a reconhecer e a incorporar a necessidade de um reordenamento na vida. ${ }^{51} \mathrm{O}$ ser humano só conseguirá defrontar-se com o sofrimento e engajar-se no enfrentamento se conseguir entender a si mesmo como alguém maior que o problema que ele possui, visualizando em sua vida outras possibilidades e potencialidades que deverá desenvolver em função da provocação gerada pelo próprio sofrimento.

\footnotetext{
${ }^{48}$ D’ASSUMPÇÃO. Sobre o viver e o morrer, p. 55.

${ }^{49}$ SELLI, Lucilda. Dor e sofrimento na tessitura da vida. In: PESSINI, Leocir; BARCHIFONTAINE, Christian de Paul de. Buscar sentido e plenitude de vida. Bioética, saúde e espiritualidade. São Paulo: Paulinas; Centro Universitário São Camilo, 2008, p. 119-120.

${ }^{50}$ SELLI. Dor e sofrimento na tessitura da vida, p. 120.

${ }^{51}$ SELLI. Dor e sofrimento na tessitura da vida, p. 120.
} 
O sofrimento nos ensina a construir a nossa identidade. É um tempo de recolhimento. O sofrimento faz alusão a uma trajetória. Por um lado, a doença remete às razões para o sofrimento; por outro, a representação ou o discurso sobre a cura remete a uma experiência de sincronia, uma vez que apresenta o inverso ao sofrimento e à doença. ${ }^{52} \mathrm{O}$ sofrimento é uma experiência humana que evoca significados desde força e fraqueza, medo e coragem, despertando emoções positivas e negativas na pessoa que sofre. Segundo Selli, o sofrimento revela a grande manifestação da extrema vulnerabilidade e heteronomia humana, pois todo e qualquer tipo de sofrimento que assola o ser humano revela-lhe a sua inteira dependência e vulnerabilidade. ${ }^{53}$

$\mathrm{O}$ sofrimento revela a vulnerabilidade humana. $\mathrm{O}$ sofrimento constitui uma realidade que acompanha a vida do ser humano em toda a sua trajetória de modos e formas diferentes. Na maioria das vezes o sentido da existência humana recobra sentido pela via do sofrimento quando se consegue resignificá-lo. Diante de uma pessoa que sofre, a atitude mais adequada é a de silêncio e solidariedade. O silêncio evoca comunhão e engajamento. A solidariedade é a atitude de estar com quem sofre e agir a seu favor. Estas atitudes remetem à igualdade de todos os seres humanos enquanto sofredores vulneráveis e necessitados. ${ }^{54}$

O sofrimento refaz o sentido da vida. É diante do sofrimento que o ser humano prova para si mesmo sua capacidade de resistir, de fazer frente às situações mais duras e adversas da vida, de atribuir um novo sentido à realidade que vive e que o cerca. Este novo sentido torna-se possibilidade de significar a situação de sofrimento e transformá-lo em espaço privilegiado de aprendizado na construção de si mesmo e dos próprios ideais de vida. Vitor Frankl é este grande exemplo, criador da logoterapia. Frankl ${ }^{55}$ critica a visão de ser humano que descarta sua capacidade de tomar uma posição ante condicionantes, quaisquer que sejam. Ele diz que uma das principais características humanas está na capacidade de elevar-se acima das condições biológicas, psicológicas ou sociológicas e crescer para além delas. O sofrimento sempre foi e sempre será uma escola imprescindível de descoberta de significados e sentido.

\footnotetext{
${ }^{52}$ RODRIGUES, N.; CARDOSO, A. C. Idéia de sofrimento e representação cultural da doença na construção da pessoa. In: DUARTE, D. F. L.; LEAL, F. O. (org.). Doença, sofrimento, pertubação: perspectivas etnográficas. Rio de Janeiro: Fio Cruz, 2001.

${ }^{53}$ SELLI. Dor e sofrimento na tessitura da vida, p. 121.

${ }^{54}$ SELLI. Dor e sofrimento na tessitura da vida, p. 122.

${ }^{55}$ FRANKL, Vitor. Em busca de sentido: um psicólogo no campo de concentração. Petrópolis: Vozes, 1991.
} 
$\mathrm{O}$ sofrimento reelabora os valores éticos porque ensina as pessoas. $\mathrm{O}$ ser humano que sofre repensa os valores, atitudes e admite a própria finitude e fragilidade humana. A vida recobra um novo sentido e abraça com todo o seu ser a humildade que consiste na aceitação da própria fragilidade. Segundo Frank $1{ }^{56}$ sofrer significa crescer enquanto que para Rosellós ${ }^{57}$, sofrer significa amadurecer.

O sofrimento é um espaço privilegiado de encontro interior e de relação com o outro. Nesta perspectiva o sofrimento constrói espaços de revelação, confidencialidade e possibilidade de abertura de si para o outro e de construção de verdadeiras amizades. Desperta confiança e capacidade de entrega, como também, sensibilidade e capacidade de compaixão e doação incondicional. Nesta relação pessoal e interpessoal o sofrimento pode ser a pedra angular no evoluir de uma relação que expressa o mais profundo do ser humano, ou seja, a capacidade de amar e bem-querer. ${ }^{58}$

O sofrimento pode nos ajudar a compreender como de fato somos. Precisamos inicialmente, aprender a nos salvar da ilusão do "eu". O "eu" é uma ilusão feita de desejos, temores, ansiedades e obsessões. O sofrimento nos ajuda a despertar. Despertar é, pois a arte de ver a natureza das coisas em si mesma, com objetividade e não com a ótica dos desejos e temores. Despertar é saber dizer "não" às expectativas, é viver na realidade que nos cerca, sem, contudo deformá-la negativamente, transformando-a em pesadelo. A experiência do sofrimento nos ensina saber esperar, utilizar o potencial de nossa mente, expressar nossas emoções, desapegar-se, pois o apego é a raiz de todos os males, de todos os sofrimentos. O próprio sofrimento nos ensina o remédio para saná-lo. Perdoar talvez seja o remédio mais eficaz para acabar com o sofrimento. ${ }^{59}$

Hoje temos, na verdade a dicotomia, a separação irreversível entre a capacidade técnica e a capacidade de discernimento. Há uma hipertrofia do conhecimento analítico e uma atrofia da capacidade do discernimento ético e da espiritualidade. Muitas vezes, o profissional da saúde está desnorteado diante das situações existenciais que o paciente lhe coloca. É necessário que os profissionais da saúde pensem suas capacidades técnico-científicas na

\footnotetext{
${ }^{56}$ FRANKL. Em busca de sentido:, 1991.

${ }^{57}$ ROSSELÓ, T. F. Antropologia del cuidar. Madrid: Instituto Borja de Bioética. Fundación MAPFRE Medicina, 1998.

${ }^{58}$ SELLI. Dor e sofrimento na tessitura da vida, p. 123.

${ }^{59}$ D’ASSUMPÇÃO. Sobre o viver e o morrer, p. 75-90.
} 
relação com as decisões éticas e existenciais. Isso não pode ser visto como um entrave para o progresso da ciência, mas como proteção às arbitrariedades do ser humano. A ciência analítica deve desenvolver a capacidade de reconhecer os problemas éticos nas ciências da vida. ${ }^{60}$ Isso significa que a ciência analítica deve deixar de reivindicar o direito de exclusividade do conhecimento científico. Quando isso se tornar factível, então haverá as condições necessárias para uma relação dialógica entre o conhecimento analítico e a sacramentalidade da vida, que incorpora as dimensões existenciais. ${ }^{61}$

$\mathrm{Na}$ ciência mecânica, a morte é vista como um grande fracasso. Tanto que os corpos são retirados secretamente, na calada da noite, pelos fundos do hospital. Será que os profissionais da saúde não são aqueles que mais sofrem com o medo do mistério da morte? Como a vulnerabilidade humana expressa sua fragilidade e sacralidade. É necessário dizer que a teologia se esforça em dar legitimidade, através da reflexão racional, às respostas existenciais do sentido último do ser, da vida e da morte. Nesta perspectiva, o profissional da saúde pode aceitar o sofrimento e a morte como uma realidade, sem se arrogar o direito de querer dar soluções tecnológicas às questões fundamentais do sofrimento e da morte do ser humano. O limite das ciências da saúde encontra-se na impossibilidade da lógica analítica de proporcionar sentido ao sofrimento e à morte. ${ }^{62}$

\section{Considerações finais}

A existência é única, marcada pela temporalidade e pela contingência. Fazer dela algo bom e realizador é passar pela angústia da compreensão da finitude, da sagrada vulnerabilidade humana, e assim, fazer o salto na fé para trazer a morte da terceira pessoa para a primeira pessoa do singular; confiar na esperança oferecida pela fé e não ter medo do fim, pois ele é a oportunidade do encontro com o infinito e esse é o objetivo supremo da constante busca do ser humano. ${ }^{63}$

\footnotetext{
${ }^{60}$ SPINSANTI, S. Ética Biomédica. São Paulo: Paulinas, 1990, p. 24.

${ }^{61}$ NEVES MARTINS, João José; REGO, Sérgio et al. (Orgs.). Educação Médica em transformação: instrumentos para a construção de novas realidades. São Paulo: HUCITEC, 2004.

${ }^{62}$ BRAKEMEIER, Gottfried. O ser humano em busca de identidade: contribuições para uma antropologia teológica. São Paulo: Paulus; São Leopoldo: Sinodal, 2006, p. 172-220.

${ }^{63}$ MARTINS. Consciência de finitude, sofrimento e espiritualidade, p. 105.
} 
A contribuição da humanidade é propor a correlação das ciências analíticas e sintéticas, apontando para o respeito ao mistério do ser humano e o resgate do caráter do sublime em meio à dominação do mundo masculino adulto, da eficiência da técnica, do lucro e da fragmentação do saber com vistas ao exercício do poder. A humanidade deve estar a serviço da preparação para a vida de todas as vidas, resgatando a poética, a estética e a admiração. Essa visão faz as pessoas sensíveis para a compaixão pelo sofrimento dos humilhados. Assim, a compreensão não é somente uma grandeza intelectual, mas de relacionamentos, que inclui o outro como uma alteridade. Entende-se aqui, que as ciências no geral, em meio às limitações do método analítico, deparam-se com novas abordagens epistemológicas que estão abertas para a integração de outras respostas possíveis, nas quais se busca a interação de saberes, incluindo o holístico e o ecológico, transcendendo o político e o econômico na sociologia e ultrapassando o técnico, o biotecnológico na medicina. ${ }^{64}$

A dimensão espiritual abre o ser humano para realidades que estão além de sua estrutura somática e psíquica. Trata-se do âmbito do sentido da vida que transcende a pura configuração histórico-existencial, possibilitando a trans-significação das contingências e abrindo o horizonte do infinito. Assim, a doença, a dor, o sofrimento e a própria morte recebem uma nova significação que ajuda a superar e a integrar essas realidades adversas. $\mathrm{O}$ espírito, como busca do sentido, encontra sua máxima expressão na simbólica religiosa. $\mathrm{O}$ espírito é a estrutura antropológica da experiência religiosa. Deus é o sentido último da existência daquele que crê. A fé configura a vida daquele que põe toda sua confiança em Deus. ${ }^{65}$

Sofrimento e morte fazem parte da existência humana. Todos passam por algum tipo de sofrimento e acabam morrendo. O ser humano é um ser para a morte e ter essa consciência de finitude; quanto mais cedo adquirida, melhor para a compreensão da existência humana, percebendo-a como existência de possibilidade e a importância de fazer escolhas para uma vida mais realizada ${ }^{66} \mathrm{~A}$ vida ao longo do seu percurso vai sinalizando com sua vulnerabilidade, tornando-a assim, santa.

\footnotetext{
${ }^{64}$ WESTPHAL. Ciência e Bioética, p. 106.

${ }^{65}$ JUNGES. As Interfaces da Teologia com a Bioética, p. 115-116.

${ }^{66}$ MARTINS. Consciência de finitude, sofrimento e espiritualidade, p. 105.
} 


\section{Referências Bibliográficas}

ABBAGNANO, N. História da filosofia. Lisboa: Presença, 1970. v. XIV.

BERMAN, Marshall. Tudo o que é sólido desmancha no ar. A aventura da modernidade. São Paulo: Companhia das Letras, 17a edição, 2000.

BRAKEMEIER, Gottfried. O ser humano em busca de identidade: contribuições para uma antropologia teológica. São Paulo: Paulus; São Leopoldo: Sinodal, 2006.

BRITO, Robson Figueiredo. Morte: experiência da vida. In: D’ASSUMPÇÃO, Evaldo A. Biotanatologia e Bioética. São Paulo: Paulinas, 2005.

BUIATTI, Marcelo. Biotecnologias. A engenharia genética entre biologia, ética e mercado. São Paulo: Edições Loyola - Paulinas, 2004.

D’ASSUMPÇÃO. Evaldo A. Sobre o viver e o morrer. Petrópolis: Vozes. 2010.

FRANKL, Vitor. Em busca de sentido: um psicólogo no campo de concentração. Petrópolis: Vozes, 1991.

GALENO, Sebastião. Medo da morte, medo da vida? In: D’ASSUMPÇÃO, Evaldo A. (org.). Biotanatologia e Bioética. São Paulo: Paulinas, 2005.

GARRAFA, Volnei. Crítica bioética a um nascimento anunciado. In: Revista Parcerias Estratégicas. Ética das manipulações genéticas: proposta para um código de conduta. Número 16 - Outubro de 2002. Brasília, p. 115-123.

JONAS, Hans. Das Prinzip Verantwortung. Versuch einer Ethik für die technologische Zivilisation. Frankfurt am Main, 1979.

JONAS, Hans. O Princípio responsabilidade. Ensaio de uma ética para a civilização tecnológica. Rio de Janeiro: Contraponto Editora; Editora PUC Rio, 2006.

JUNGES, José Roque. As Interfaces da Teologia com a Bioética. In: Perspectiva Teológica. 37 (2005), p. 105-122.

JUNGES, José Roque. Bioética. Perspectivas e desafios. São Leopoldo: Editora Unisinos, 1999.

KÜBLER-ROSS, Elizabeth. Sobre a morte e o morrer. São Paulo: Martins Fontes, 1994. 
KÜNG, Hans. Projeto de ética Mundial: Uma moral ecumênica em vista da sobrevivência humana. $3^{\mathrm{a}}$ ed. São Paulo: Paulinas, 2001.

KURY, Mário da Gama. In: Ésquilo; Sófocles; Eurípides. Prometeu acorrentado. 2. ed. Rio de Janeiro: J. Zahar, 1998, p. 9-12 (A tragédia grega; v. 6).

LEGRAND, Gerard. Dicionário de Filosofia. Lisboa: Edições 70, 1986.

LEPARGNEUR, H. Lugar atual da morte: antropologia, medicina e religião. São Paulo: Paulus, 1986.

MARTINS, Alexandre Andrade. Consciência de finitude, sofrimento e espiritualidade. In: PESSINI, Leocir; BARCHIFONTAINE, Christian de Paul de (org.). Buscar sentido e plenitude de vida. Bioética, saúde e espiritualidade. São Paulo: Paulinas; Centro Universitário São Camilo, 2008, p. 99-107.

MARTINS, Hermínio. Hegel, Texas: temas de filosofia e sociologia da Técnica; Tecnologia, Modernidade e Política. In: Hegel, Texas e outros ensaios de teoria social. Lisboa: Edições Século XXI, 1996.

NEVES MARTINS, João José; REGO, Sérgio et al. (Orgs.). Educação Médica em transformação: instrumentos para a construção de novas realidades. São Paulo: HUCITEC, 2004.

OWEN, M. J. La sabiduría de la vulnerabilidad humana. In: Dolentium Hominum, 22, (1993), p. 171-173.

PESSINI, Leocir; BARCHIFONTAINE, Christian de Paul. Problemas atuais de Bioética. São Paulo: Centro Universitário São Camilo, Edições Loyola, 2000.

PORTO, Dora. Tecnologia \& ideologia: os dois lados da moeda que produz vulnerabilidade. In: Revista Brasileira de Bioética. Volume 2 - Número 1 - 2006. Brasília, p.63-86.

RODRIGUES, N.; CARDOSO, A. C. Idéia de sofrimento e representação cultural da doença na construção da pessoa. In: DUARTE, D. F. L.; LEAL, F. O. (org.). Doença, sofrimento, pertubação: perspectivas etnográficas. Rio de Janeiro: Fio Cruz, 2001.

ROSSELÓ, T. F. Antropologia del cuidar. Madrid: Instituto Borja de Bioética. Fundación MAPFRE Medicina, 1998. 
SELLI, Lucilda. Dor e sofrimento na tessitura da vida. In: PESSINI, Leocir; BARCHIFONTAINE, Christian de Paul de. Buscar sentido e plenitude de vida. Bioética, saúde e espiritualidade. São Paulo: Paulinas; Centro Universitário São Camilo, 2008.

SGRECCIA, Elio. Manual de bioética I. São Paulo: Edições Loyola, 2002.

SIBILIA, Paula. O homem pós-orgânico. Corpo, subjetividade e tecnologias. Rio de Janeiro: Relume Dumorá, 2003.

SPINSANTI, S. Ética Biomédica. São Paulo: Paulinas, 1990.

TORRALBA i ROSELLÓ, Francesc. Antropologia do Cuidar. Petrópolis: Vozes, 2009.

WESTPHAL, Euler Renato. Ciência e Bioética. Um olhar teológico. São Leopoldo: Editora Sinodal, 2009.

\section{Waldir Souza}

Doutor em Teologia pela PUC-Rio. Professor de antropologia teológica, bioética e teologia moral no Bacharelado em teologia da PUCPR, Curitiba/PR. Colaborador do PPG em teologia da PUCPR. E-mail's: waldir.souza@pucpr.br ; wacasouza@yahoo.com.br

Artigo Recebido em 29/08/2011

Artigo Aprovado em 29/02/2012 